\title{
DETERMINATION OF OPTIMAL SECURITY EQUIPMENT FOR HYPOTHETICAL NUCLEAR WASTE STORAGE FACILITY
}

\begin{abstract}
A variety of different security systems and components are commercially available. Before implementing a security system, it is important to understand the characteristics and requirements of the area and facility to be protected and possible path elements to penetrate a facility, with this understanding, detailed and specific criteria can be developed to specify exactly how the security system should be implemented and optimized. Technology and manufacturers of security devices are rapidly changing to meets the new tactics of the adversaries. This work explains how to determine the optimal security equipment should be used to protect and detect the penetration process for nuclear waste storage facilities. It is hazards and danger facilities. It contains radioactive materials and sources. This paper presents the idea and the concept of how the development and installation of electronic equipment to detect penetration of the facility and the use of a variety of electronic sensors for each element traffic access to the nuclear facility, such as the detectors; vibration detector, passive infrared to detect the movement of people, and the detector of break the glass and open doors. Select cameras surveillance system to estimate the alarm real or wrong. The paper discusses the reasons for choosing this security equipment to achieve an acceptable level security. After determination and installation process of the security system the evaluation process by computer program are achieved to insure the level of security system is accepted and it meets the physical protection requirements in the form reassuring nuclear facility.
\end{abstract}

\section{INTRODUCTION}

Many types of security and intrusion detection equipment are in use today, to determine the optimal security equipment; the utilities should base their decisions on their Design Base Threat (D.B.Ts), as well as other operational and design considerations. A variety of security 
systems and components are commercially available. Before implementing a security system, to determine the type of security system to install, it is important to understand the characteristics of the area to be protected, as well as the security expectations and requirements [1]. This work introduces the idea and phenomena, of the vibration detectors, motion detectors and glass breakage security equipments. The coverage areas and the protected distances will be explained and alarm assessment will be discussed. The nuclear waste storage facilities are hazards and danger facilities'. It contains radioactive materials and sources which may be damaged, and hazards to exposure. The security equipment should be suitable and reliable. It depends on the facility contracture, outside areas and ambient [2].

\subsection{Hypothetical nuclear waste storage (NWS)}

NWS Site Description: The waste storages area is a simulation site for implementation the design process of the physical protection system (PPS). NWS site contains many of storages and tombs; some of them are small and the others are big storages. Figure (1) shows the outside view of a hypothetical big waste storage facility has nuclear materials and radiological sources stored in drums and containers. The storage build is consists of two parts: Bottom part; forms by cement blocks (4meters height), and Top part; created from metal sheet as umbrella (3meters height).

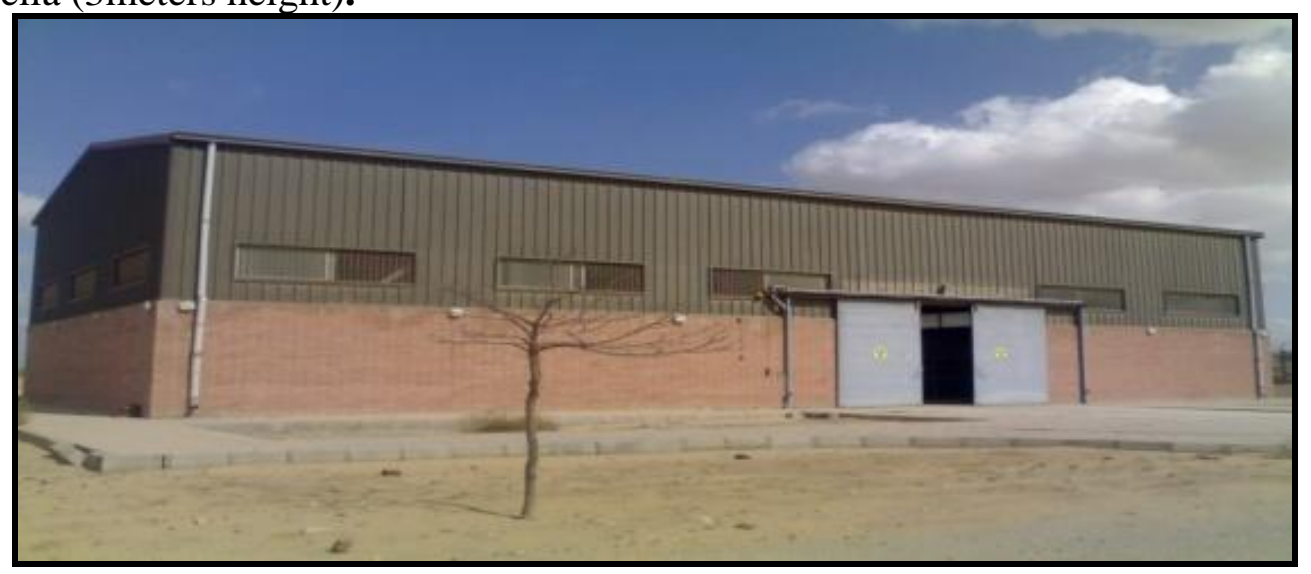

Fig. (1) Hypothetical nuclear waste storage

From the security point of view; the stored materials is attractive targets for terrorists and it should be more secured to prevent the sabotage and theft events. This work will determine the optimal security equipment should be determined and used for protection the waste storage.

The work will concentrate on the intrusion detection sensors and alarm system. Figure (2) illustrates the waste storage internal view. Inside the storage a horizontal top mounted ceiling crane used to move the waste drums and sources shield units [3].

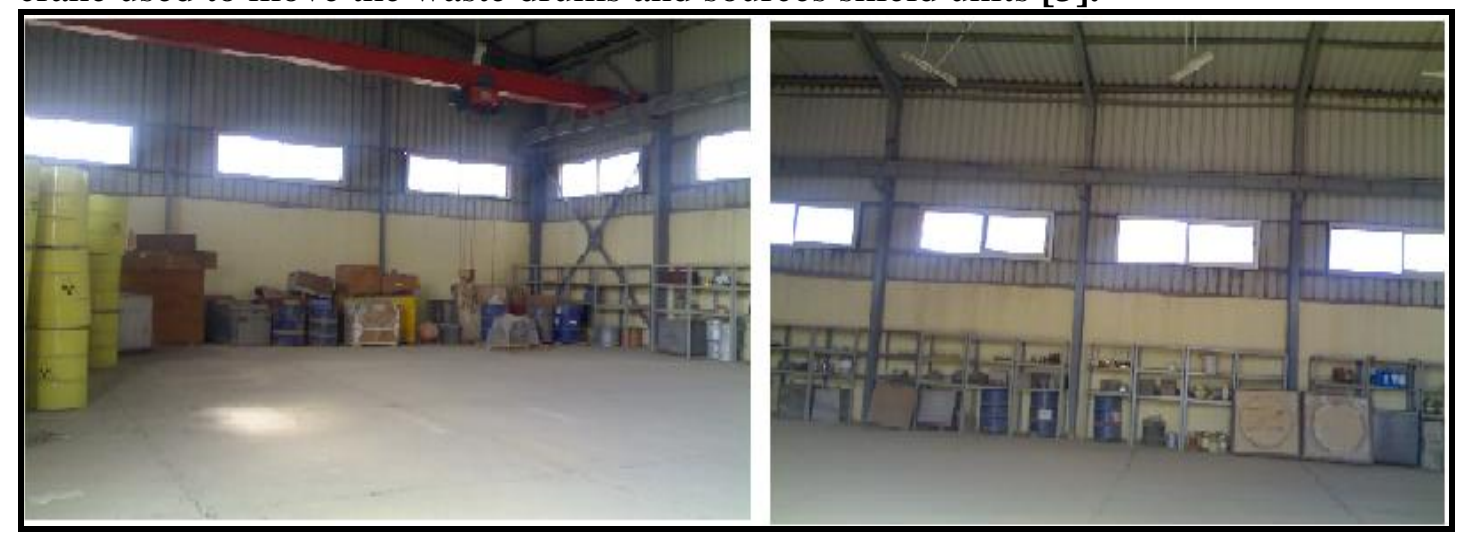

Fig. (2) Waste Storage Internal view

The waste storage dimensions: are, Width $=15$ Meters, Length $=28$ Meters, Height $=7$ Meters; (Flat $=4$ Meters, and umbrella metal sheet $=3$ Meters) 


\subsection{Waste Storage Path Elements}

Paths Elements or the adversary ways (Traffic entry points) to penetrate the waste storage facility is shown in figure (3)

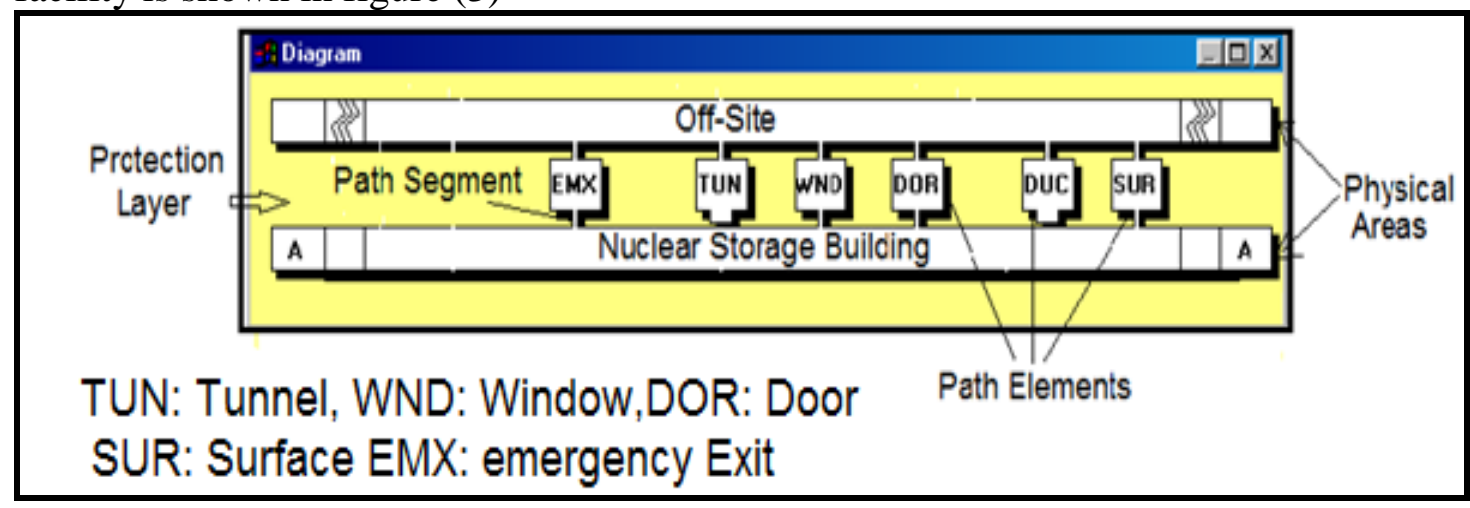

Fig. (3) Waste Storage Path Elements

The possible paths elements can be used by the adversaries to enter the storage explained in fig (3) are:-

1. Main Entrance Door,

2. Emergency Door,

3. Glass Windows on the top of the build (Four sides),

4. Duct hole (Mesh Grilled shape),

5. The surface of the storage (Ceiling and Walls), and

6. Tunnel under ground made by Adversary (fig (3) illustrates path segments)

\section{Choosing of Optimal Security Equipment}

The types of security equipment employed will be dependent on

- The design basis threat (DBT). Question to consider include: What tactics, motivation, skills, knowledge, tools, or weapons might the adversary use? and

- The characteristics of the area (humidity, temperature conditions, and wind conditions exist); that the equipment will be expected to cover are critical factors that need to be taken into account.

- Area dimensions and type or region to be protected. Before selecting the security equipment, the ambient noise levels, thermal conditions, or vibrations and the small animals near the protected space should be viewed and pointed. Also, the outside areas to be protected should have a lower nuisance alarm rates [4].

\subsection{The optimal physical security equipment}

Once the utility understands the characteristics of the area to be protected and the security expectations and requirements, the utility can determine the type of security equipment to use. There are many different types of security systems, and most of them depend on the cluster sensors, as:-

- Access control systems (Card Readers, PIN Access, and Biometrics)

- Interior and Exterior Intrusion detection system (detection and alarm)

- Closed circuit television (CCTV) surveillance system

This work introduces: determination of optimal intrusion detection security equipment and sensors

\subsection{Interior boundary penetration sensors}

Boundary penetration sensors detect the presence of an intruder across an interior boundary, such as a door, window, or hatch. The most typical boundary penetration sensors are door switches, glass-break sensors, and linear-beam sensors.

\subsection{Exterior intrusion detection}

Several types of exterior intrusion detection sensors exist and may be classified according to type, method of use, style, and mode of application. The following exterior systems are most applicable to water system applications and are listed in order from basic to be advanced in the following paragraphs: freestanding sensors, buried-line sensors, and fence-mounted sensors. After studying the nuclear waste storage facility, and design basis threat information, the adversaries will intent to attack the waste facility to make theft or a sabotage event against 
a nuclear facility and may create a radiological hazard to the personnel, and a potential radioactive release to the public and the environment inside the location or at another place. The around area of the waste storages have the following characteristics: Desert area and it is dust and windy, high temperature, and contains a lot of small animals near the protected space, which can generate many false and nuisance alarms. There are many sources of magnetic field which can generates lighting surges and make interference with the light beams security equipment

\subsection{Exterior and interior intrusion detection choosing}

Choosing the optimal security detector depends on the previous study of the waste storage facility site (DBT, characteristics and conditions), the experimental and technical experience, and the suitability of the security detectors. From hundreds of security detectors; the following exterior and interior equipments has been selected

\subsubsection{Exterior intrusion detection system (EIDS)}

According to study of waste storage area and characteristics and the factors can effects on the physical operation of the equipment, the optimal exterior intrusion detection security equipment, will be photoelectric detectors AX-PLUS model, which will discuss below

\subsubsection{Interior intrusion detection system (IIDS)}

The waste storage facility should be secured and intrusion detection for all path elements to enter a facility, they are Main Entrance Door, Duct hole and the Glass windows, the following section shows how to select the optimum and suitable security equipment

\subsubsection{Main entrance door security equipment determine}

Security equipment selected for main entrance and emergency doors is Open Door (O.D) Sensor and Balanced Magnetic Switch (BMS). Main entrance door is one of the traffic paths elements to reach the inner area.

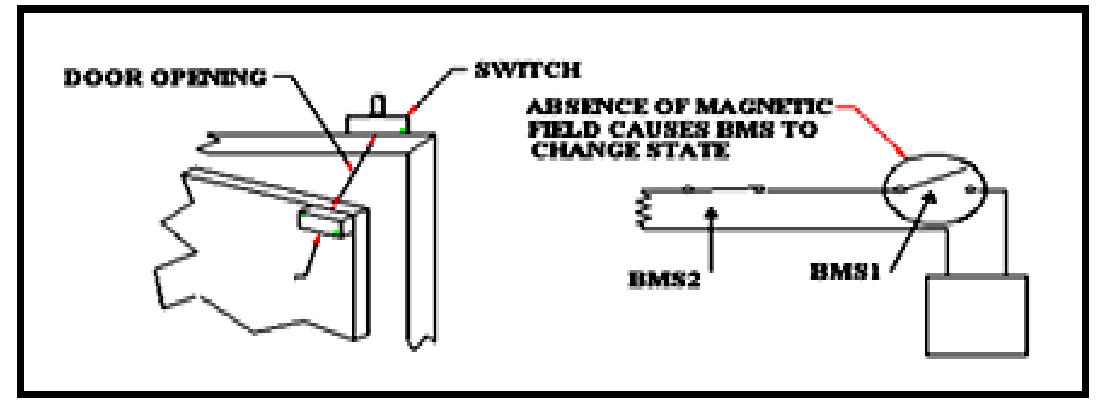

Fig. (4) Open Door Sensor Position with BMS

BMS is very important it prevent unauthorized access. The open door (O.D) sensor is used to detect the intrusion via the emergency door. OD sensors installed on the top door edge. Figure (4) shows the OD position, when the door is closed, the reed switch is held in the balanced or center position by interacting magnetic fields. If the door is opened or an external magnet is brought near the sensor in an attempt to defeat it, the switch becomes unbalanced and generates an alarm [5].

OD sensor advantaged with the following:

- Low cost, low power consumptions, very reliable sensor and recommended to use with balanced magnetic switch (BMS)

- Difficult to enter via door without alarm generation,

- Depends on the magnetic field, have a lower nuisance and false alarm rates,

- Not affects by humidity, temperature conditions, and wind conditions exist,

\subsubsection{Interior volumetric sensors selection}

Monitor an internal area to detect the presence of an intruder. There are several types of volumetric sensors, including microwave, ultrasonic, electric field, and passive infrared (PIR) sensors. According to the facility study and viewing the waste storage facility contain a top mounted ceiling crane and it is used to move the waste drums and sources shields, the crane motions generates vibration, air motion, sonic effect and noise disturbance. So that: we should discard each of microwaves, ultrasonic, and electric field volumetric sensors. The 
optimum and suitable security intrusion detection equipment is PIR sensors; the PIR field of view is illustrated in figure (5).

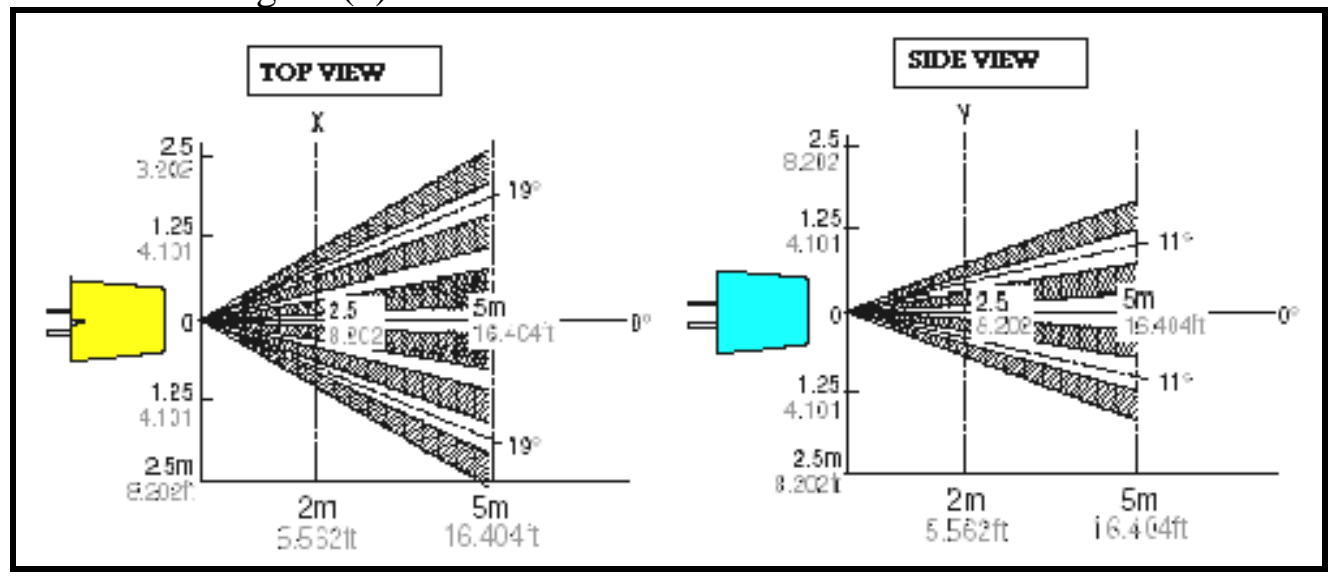

Fig. (5) PIR field view dimensions

\subsubsection{Ventilation hole (Duct) security equipment choosing}

The waste storage facility contains a weak point it is the Ventilation hole (Duct), this path elements is very danger from the security point of view. The suitable security equipment is Passive infrared sensors (PIR), PIR motion sensors detects a change in the thermal energy pattern caused by a moving intruder and initiate an alarm when the change in energy surrounding environment. PIR used to cover the inner areas of the storage by generates alarm when intruder passing through its detection region (field region), these sensors are passive devices. All objects with temperatures above absolute zero radiate thermal energy. The wavelengths of the IR energy spectrum lie between 1 and 1,000 microns. Because the human body radiates thermal energy of between 7 and 14 microns, PIR motion sensors are typically designed to operate in the far IR wavelength range of 4 to 20 microns [6].

\subsubsection{Passive infrared sensors technical specifications}

Depending on the waste storage inner area and distances to be protected and the outside and inside temperature and weather conditions; the optimum PIR module can be selected as:

View Field $=(5 \times 5 \times 10)$ meters $(\mathrm{W} \times \mathrm{H} \times \mathrm{L})$,

Vertical angle (-11 to 11$)$, Horizontal angle (-19 to 19$)$

Worked ambient temperature $=-20 \mathrm{C}$ to $60 \mathrm{C}$,

Non-detection currents $=0$ to $2.5 \mathrm{~mA}$

Power supply voltage $=7 \mathrm{VDC}$,

Detection Current $=15 \mathrm{~mA}$

The PIR dimensions and field view is illustrated in figure (5).

Choosing type: is 6 unit of MP Motion Sensor (AMN1, 2, 4), 10 meters detection type connected to a main control panel for alarms generation and it is installed 2meters far from the duct hole to cover $50 \mathrm{~cm}$ hole dimension with 19 angle of degree from inside area [7]. Also PIR installed inside four corners of the inner area to cover it by 45 angle of degree [8].

\subsubsection{Glass Windows security equipment choosing}

A Glass window is one of the path elements and points to make intrusion into facility. Glassbreakage sensor is a device that uses to cover this intrusion.

\subsubsection{Glass-breakage sensors (G.B)}

A glass break sensor is any device intended to detect the breakage of protected glass. The noise from breaking glass consists of frequencies in both the audible and ultrasonic range. Glass-breakage sensors use microphone transducers to detect the glass breakage.

Operating Principle: Glass-break sensors (G.B) use a microphone to listen for frequencies associated with breaking glass. A processor filters out all unwanted frequencies and only allows the frequencies at certain ranges to be analyzed. The 
processor compares the frequency received to those registered as being associated with the breaking of glass. If the received signal matches frequencies characteristic of breaking glass, then an alarm is generated [9].

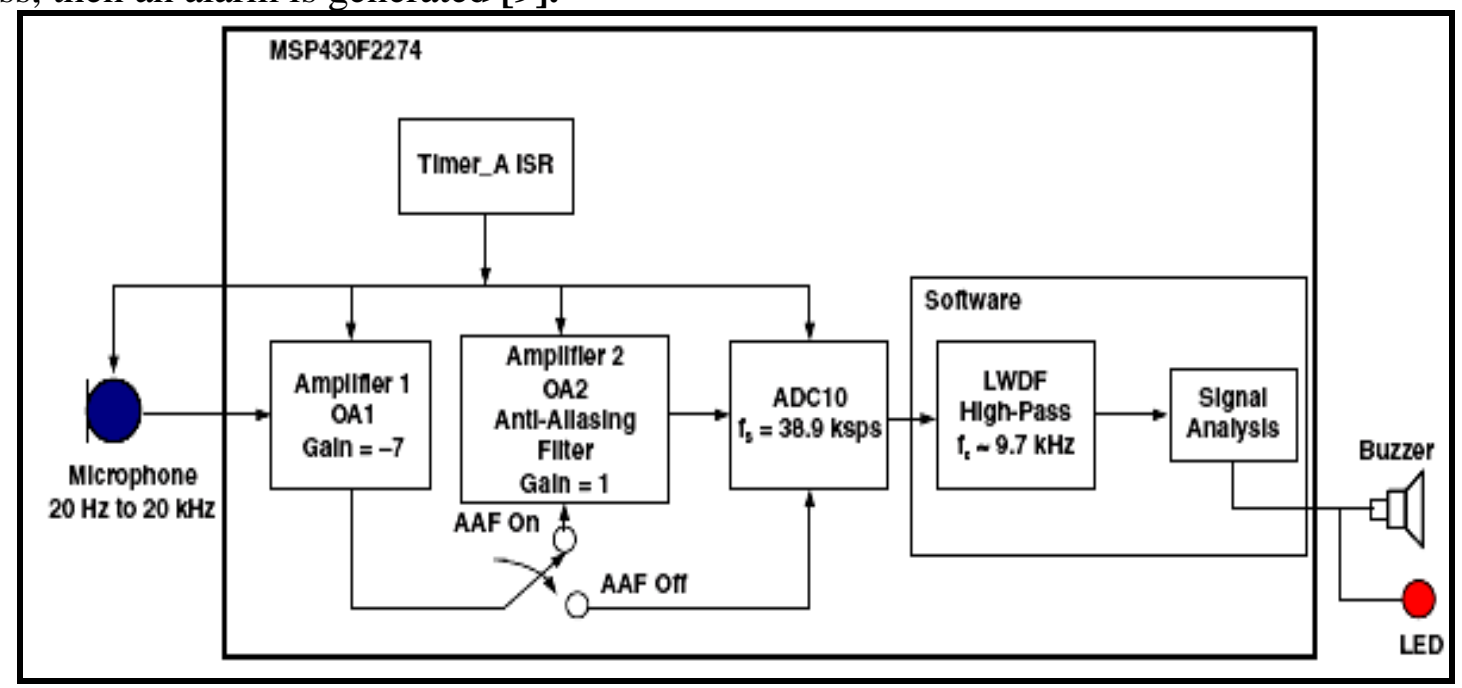

Fig. (6) Setup for glass breakage detector using (MSP430F2274)

\subsubsection{G.B sensor general technical specifications}

Selected type: GFD-20 audio discriminator G.B sensor type, is a 16-bit microcontroller, MSP430F2274 unit,

Worked ambient temperature $=(-20 \mathrm{C}$ to $60 \mathrm{C})$,

Power supply voltage $=(9$ to 16$)$ VDC,

Detection Current $=20 \mathrm{~mA}$, Alarm period $=(2-3) \mathrm{Sec}$,

Detection range $=15$ meters radius adjustable,

Coverage area $=$ up to $500 \mathrm{sqrt} / \mathrm{m}$, Cut out frequency $=(2-10) \mathrm{kHz}$,

The current consumption of $0.7 \mathrm{~mA}$ during standby mode and active mode current of just 250 $\mathrm{mA}$ at $1 \mathrm{MHz}$ make this device an excellent choice for battery-powered applications. Figure (6) shows the setup for the glass breakage detector using this device.

According to the storage dimension, Length $=28$ Meters, Width $=15$ Meters, and the detection range of the choosing GB sensor which; is 15 meters, so that the numbers of glass breakage sensors should be used are 6 devices connected to a main control panel for alarms generation. Each device installed behind the glass windows from inner area and it is distributed as follows:

- 1 GB sensors on the front view, 2 GB sensors on the back view

- 1 GB sensors on the left view, 1 GB sensors on the right view

GB sensor it is recommended to use because it is advantaged by the following; a high detection range, Low cost, Low power consumptions and suitable sensor for glass

\subsection{Vibration Detector (VB.D)}

The next path element to make intrusion into facility is the building surface. The security detectors can used to cover this point and also can detects any intrusion by using tunnels under the facility. VB.D is used on windows, doors, ceilings and floors for early detection or burglary attempts. The vibration detector is screwed onto the surface to be monitored; as brick or concrete, walls, (VB.D installation in figure 8). 


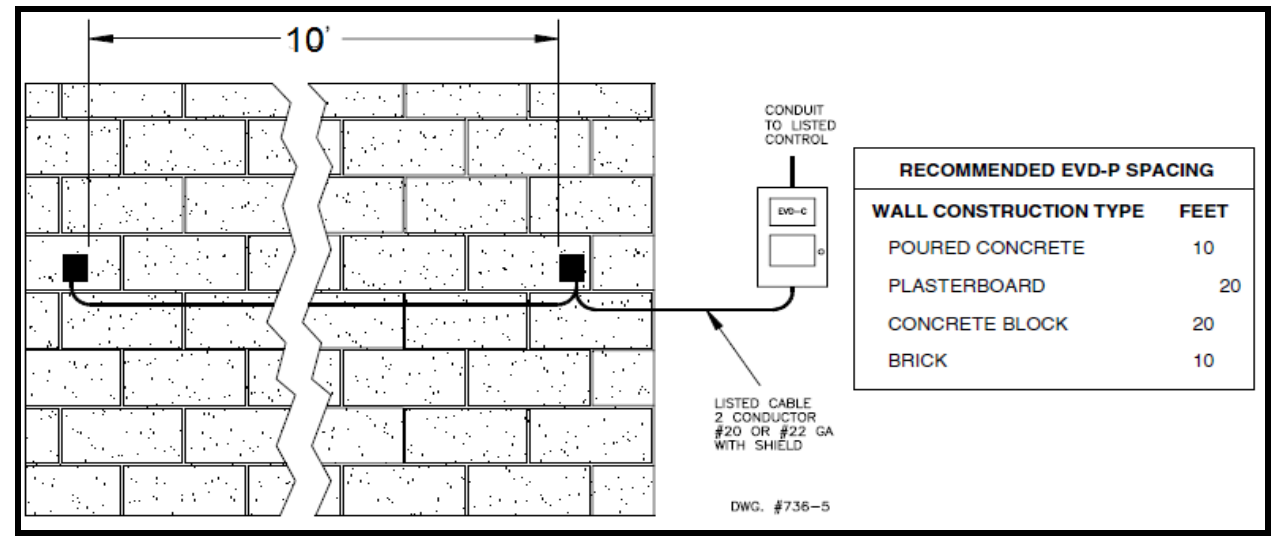

Fig. (8) Vibration detector installation

VB.D advantages are: Effective on a wide variety of materials, and High sensitivity, High immunity to environmental disturbances, Microprocessor-assisted signal evaluation, Adjustable sensitivity, and Low current consumption, see VB.D circuit in figure (7)

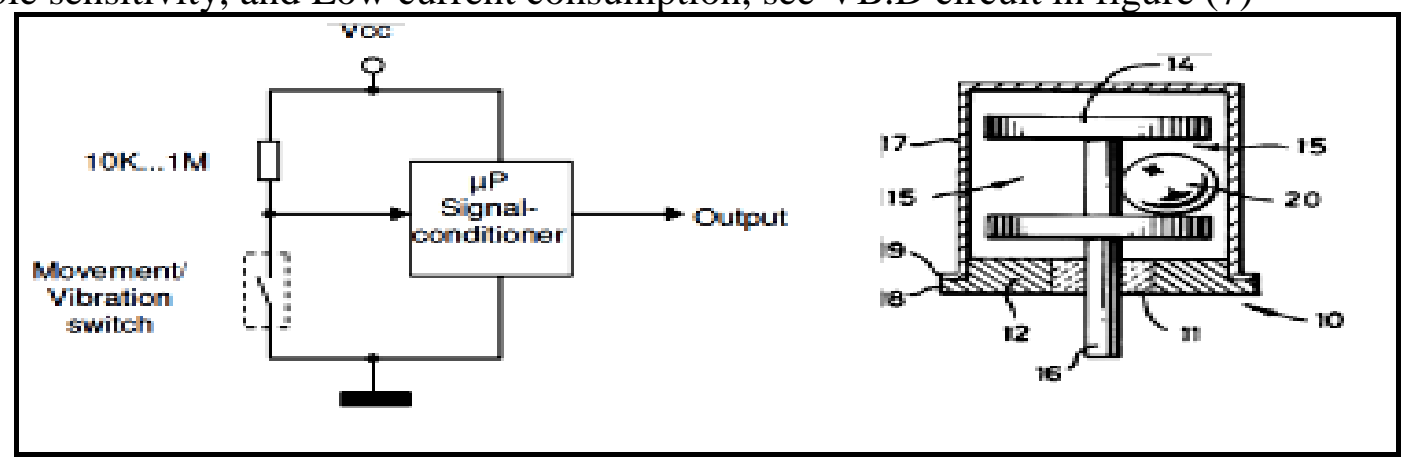

Fig.(7) Vibration detector circuit

According to the storage dimension; The distance and covered region of this type is 10 FEET for Bricks, so that we use total

8 VB.D units; the number according to the walls distances of waste storage facility and its distribution as follows:

- VB.D should be installed at the top ceiling of storage

- VB.D putted on the front surface and 2 at the back surface

- One detector putted at the left surface, and one at the right surface

\subsubsection{Vibration detector technical specifications}

Dimensions: 12 1/4"H x $83 / 8$ "W x $31 / 8 " \mathrm{D}, 31.1 \mathrm{~cm} \mathrm{H}$ x $21.3 \mathrm{~cm} \mathrm{~W}$ x $7.9 \mathrm{~cm}$ D, Weight: 8 lbs., 3.6 kg., Enclosure: 18 Gauges - Cold Rolled Steel, Power Input: 12VAC, 20VA, 60Hz, Operating Voltage: 6VDC

Typical Current: 20mA, Alarm Current: $25 \mathrm{~mA}$,

Contact Ratings: Alarm Relay and Tamper Switch,

1.0 Amp at 28VDC, 0.1 Amps at 130VD

\subsection{Waste storage alarm assessment (Camera Selection)}

A Closed Circuit Television System (CCTV) is essential to identify the cause of an alarm and to determine if an alarm is true or false. With a CCTV System, security personnel can rapidly assess sensors alarms at remote locations. The CCTV System has two purposes. The first is to determine the cause of a sensor alarm. This includes determining whether the alarm is a true or false alarm. The second purpose is to provide information about an intrusion. Cameras are mounted to allow a complete visibility of the clean zone internal area, to the Security Personnel. Cameras are installed on the four cornels of the storage (As illustrates in figure (9)) to covers the inner area, each camera cover 10 meter wide distance and from (20-40) meters length 


\subsubsection{Cameras Numbers and Specifications}

A total of 4 (four) "Microdigital indoor Fixed and colored Camera Box Type"should be used inside storage internal area, see figure (9). According; the internal area dimension the wide distance is 15 meters, the longitudinal distance is 28 meters, and height is 7 meters; from camera formulas; the selected camera has the following specifications:

- Camera image sensor: $1 / 3$ " Color CCD Video

- Resolution: 600TV lines, C/CS Mount Lens

- Min Illumination: 0.01 LUX and 0.0 LUX for IR conditions

- Lenses type : fixed $6 \mathrm{~mm}$, IR led distance 20 meters

- Input voltage Dc 12 volt, Power Supply, 50-60HZ

\subsection{Waste Storage Optimal Security Equipment}

The final step is distribution of the optimal security equipment and determines the minimum security requirements with acceptable level.

Figure (9), shows the security detectors locations inside and outside the nuclear waste storage facility. There are motion detection sensor (PIR) detects any motion inside the storage covers the inner areas, in addition to glass-breakage sensors detects glass break sound this for windows to be secured. Also the figure illustrates the vibration detection cable sensor to detect any intrusion process for the waste storage walls. Open door sensors generate alarm for door penetration. Camera system determines the cause of a sensor alarm is true or false alarms. Finally, and according to figure (3); all waste storage path elements became more secured

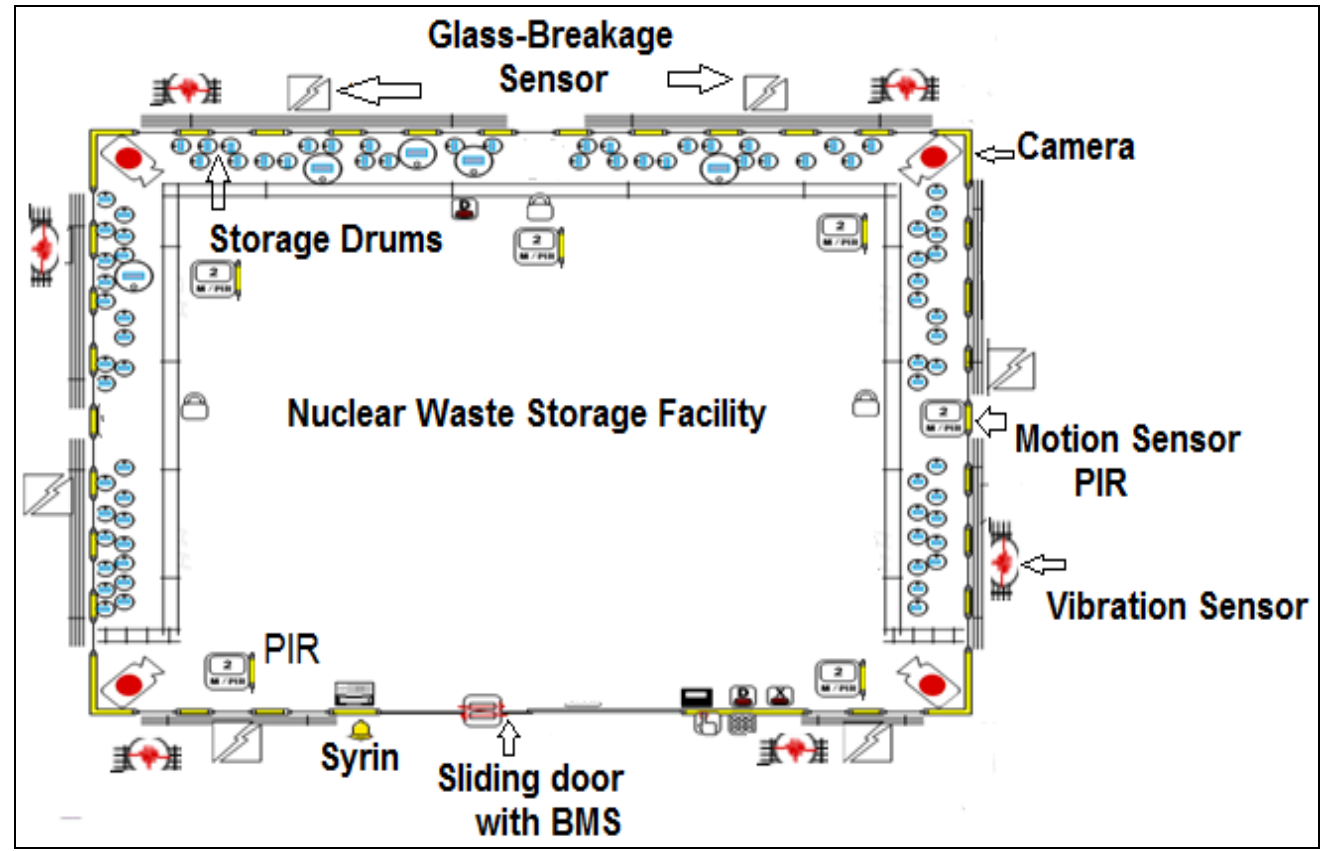

Fig. (9) Waste storage security equipment (Plane-View)

\subsection{Waste Storage Physical Protection System Evaluation process}

After designed process, the Physical Protection System of a facility must be analyzed and evaluated to ensure it meets the physical protection objectives

The Probability of interruption $\mathbf{P}$ (I) should be computed as a metric of the physical protection system effectiveness of the hypothetical facility.

Estimate of Adversary Sequence Interruption (EASI) Program will be used to calculate it [9]. The EASI model, which runs on a PC, is a simple-to- use model that quantitatively illustrates the effect of changing physical protection parameter along a specific path. It uses detection, 
delay, response, and communication values to compute the probability of interruption, but, since EASI is a path- level model, it can only analyze one adversary path or scenario at time.

\subsubsection{Probability of interruption determination}

P (I) can be computed by using EASI program; In the EASI model, input parameters representing the physical protection functions of detection, delay, and response are required. All inputs refer to a specific adversary path. The following parameters must be delivered to the EASI

- Adversary path sequences scenario,

- Probability of Detection $\left(\mathrm{P}_{\mathrm{D}}\right)$, Mean Time $(\mathrm{MT})$,

- Response Force Time (RFT), and Location Variable (B-M-E), (Begin, Middle, and End), and

- Standard of Deviations (S.D) will be used as a

$30 \%$ from mean value [2],

- Probability of Alarm Communications (PC) value should be accept level for waste storage facilities, so that it will be Used 0.95 [7].

\subsubsection{Suggestion of adversary sabotage scenario}

To use EASI program and run it to obtain the probability of interruption P (I) as an output results we should create a worst case scenario (weakness path and sabotage event) for the adversary work who intent to attack the waste storage facility. The Expecting of adversary traveling scenario is illustrated in table (1).

Table (1) Expecting of Adversary Traveling Sabotage Scenario

\begin{tabular}{|c|l|c|c|c|c|}
\hline & & & & \multicolumn{2}{|c|}{$\begin{array}{l}\text { Delays } \\
\text { (in Seconds): }\end{array}$} \\
\hline Task & \multicolumn{1}{|c|}{ Description } & $\begin{array}{l}\text { Probability } \\
\text { of Detection }\end{array}$ & Location & Mean & $\begin{array}{c}\text { Standard } \\
\text { Deviation }\end{array}$ \\
\hline 1 & Off-Site & 0 & E & 0 & 0 \\
\hline & $\begin{array}{l}\text { Enter waste storage via } \\
\text { metal bar glass } \\
\text { window }\end{array}$ & 0.6 & B & 35 & 10.5 \\
\hline 3 & $\begin{array}{l}\text { Go through waste } \\
\text { storage inner area }\end{array}$ & 0.8 & M & 4 & 1.2 \\
\hline 4 & $\begin{array}{l}\text { Locate waste targets \& } \\
\text { set explosives (T.N.T) }\end{array}$ & 0.92 & B & 30 & 9 \\
\hline 5 & Finish the mission & 0 & E & 0 & 0 \\
\hline
\end{tabular}

The probability of detection $\left(\mathrm{P}_{\mathrm{D}}\right)$ for all sensors areas had been calculated according the $\mathrm{P}_{\mathrm{D}}$ estimation's of the sensors from published tables by Sandia national laboratories [9]. Also barrier's delay times calculated, depends on the miscellaneous barrier's type, shapes and thickness (walls, doors, others), and data delivered to EASI model [5].

\subsubsection{EASI model output results}

After the data are delivered to the program and operate the EASI program, the following results can be obtained: Probability of interruption, $\mathbf{P}_{\mathbf{I}}=\mathbf{0 . 8 9}$ and the adversary finishes his task in Time delay, $\mathbf{T D}=\mathbf{6 9}$ sec. Figure $(10)$ shows the relationship between $P_{I}$ and $P_{D}$ with the system response points along the overall path of the adversary. 


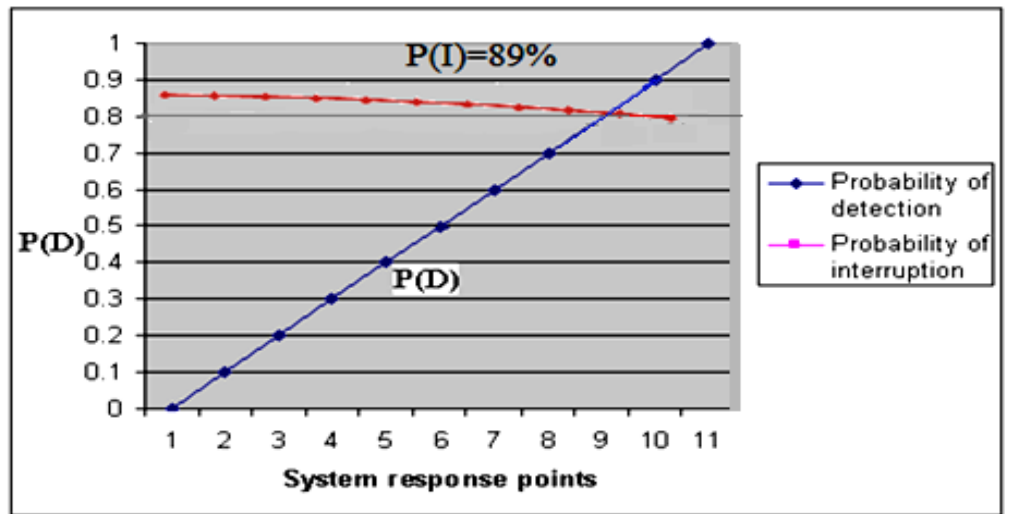

Fig. (10) Probabilities of Interruption and Detection Relationship

The acceptable level for the waste storage facilities; P (I) should be above of 85\% [7], and from the output obtained results the determination of security equipments is accepted and meets the requirements

\section{CONCLUSION}

The objective of a security system is to prevent radiological sabotage and/or theft of nuclear materials present within the nuclear facility. Choosing the optimal security detector depends on early study of the nuclear facility site (DBT, characteristics and conditions). Once the utility understands the characteristics of the area to be protected and the security expectations and requirements, the utility can determine the type of security equipment to use. The designer must begin by gathering information about the nuclear facility, the designer then need to define the threat and the path elements to be protected. Next design the system by determining how best optimal security equipment and the suitable intrusion detectors should be used depends on the facility information and security device suitability. After designed process, the Physical Protection System of a facility must be analyzed and evaluated to ensure it meets the physical protection objectives. The Probability of interruption P (I) should be computed as a metric of the physical protection system effectiveness of the nuclear facility. The final step is to make the redesign process of the physical security system of the facility if needed.

\section{REFERENCES}

[1] John H. Large, Mycle Schneider, "International Terrorism-The Vulnerabilities And Protection Of Nuclear Facilities" University Of Oxford, December (2002).

[2] Donnie D. Glidewell "Considerations For Use Of Physical Protection System Components In International Safeguards Applications" Esarda Bulletin No. 32, March (2004).

[3] William K. Paulus, Sabina Ertez Jordan, Martha Moore And Junko Mondragon, "The Assess Neutralization Analysis Module", Department Of Energy, Usa, De-Ac04-76dp00789 (2003).

[4] R. Hibbs, M. Soo Hoo, "Variations On Achieving An Effective Physical Protection System" Iaea-Cn-68/33 (2004).

[5] Marry Lynn Garcia," The Design And Evaluation Of Physical Protection Systems", Butterworth-Heinemann, Elsevier Science (Usa) (2001).

[6] G. Bunn, F. Steinhausler \& L. Zaitseva, "Report: Strengthening Nuclear Security Against Terrorists And Theives Through Better Training", Stanford University-Cisac Project, Usa (2001).

[7] International Seminar On Essential Elements Of Nuclear Security, Held At The Anl, Argonne, Illinols, Usa, 13-24 May (2013).

[8] James D. Williams, "Physical Protection System Design And Evaluation", Iaea-Cn-68/29, Vienna, 10-12 November (1997).

[9] $18^{\text {th }}$ International Training Course, "Physical Protection Of Nuclear Facilities And Materials", Sandia National Laboratories, Albuquerque, New-Mexico, Usa, (2004). 